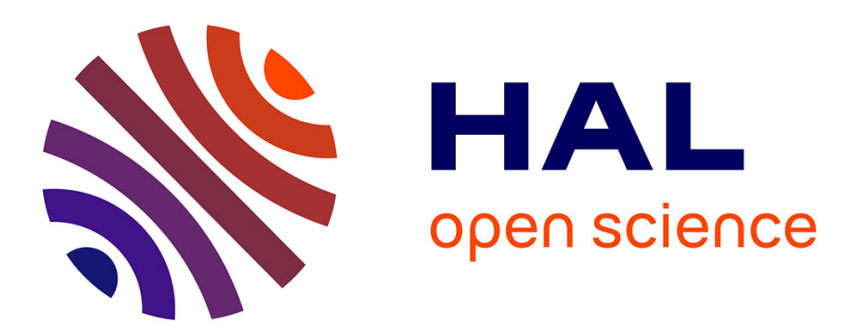

\title{
Adsorption of Sodium Dodecyl Sulfate and Sodium Dodecyl Benzenesulfonate on Poly(Vinyl Chloride) Latexes
}

\author{
Hugo Vale, Timothy Mckenna
}

\section{To cite this version:}

Hugo Vale, Timothy Mckenna. Adsorption of Sodium Dodecyl Sulfate and Sodium Dodecyl Benzenesulfonate on Poly(Vinyl Chloride) Latexes. Colloids and Surfaces A: Physicochemical and Engineering Aspects, 2005, 268, pp.68-72. 10.1016/j.colsurfa.2005.05.061 . hal-00004745v2

HAL Id: hal-00004745

https://hal.science/hal-00004745v2

Submitted on 30 May 2005

HAL is a multi-disciplinary open access archive for the deposit and dissemination of scientific research documents, whether they are published or not. The documents may come from teaching and research institutions in France or abroad, or from public or private research centers.
L'archive ouverte pluridisciplinaire HAL, est destinée au dépôt et à la diffusion de documents scientifiques de niveau recherche, publiés ou non, émanant des établissements d'enseignement et de recherche français ou étrangers, des laboratoires publics ou privés. 


\section{Adsorption of Sodium Dodecyl Sulfate and Sodium Dodecyl Benzenesulfonate on Poly(Vinyl Chloride) Latexes}

Hugo M. Vale and Timothy F. McKenna*

CNRS-LCPP/ESCPE-Lyon, BP 2077, 43 Blvd du 11 novembre 1918, 69616

Villeurbanne Cedex, France

*Tel.: +33-4-724-31775; Fax: +33-4-724-31768; E-mail: $\underline{\text { mckenna@cpe.fr }}$ 


\begin{abstract}
The adsorption of sodium dodecyl sulfate (SDS) and sodium dodecyl benzenesulfonate (SDBS) on poly(vinyl chloride) (PVC) latex particles was investigated. Conductometric titrations were performed to determine the area per surfactant molecule at various temperatures $\left(20-50^{\circ} \mathrm{C}\right)$ and the adsorption isotherms of both emulsifiers were determined at $20^{\circ} \mathrm{C}$ from surface tension titration curves. The adsorption data show some deviation with respect to the Langmuir isotherm due to their slight S-shape. The data can nevertheless be fitted very well with a limiting form of the general adsorption equation proposed by Zhu and Gu (Adv. Colloid Interface Sci. 37 (1991) 1).
\end{abstract}

Keywords: Adsorption isotherm; Langmuir isotherm; Latex; Poly(vinyl chloride); Tensiometry. 


\section{Introduction}

The adsorption of surfactants on polymer surfaces is an important issue in various industrial processes, namely because of its direct bearing on the colloidal stability and rheological behavior of polymer latexes [1,2]. Emulsion polymerization is one of the best examples of such processes. Indeed, surfactant partition plays a key role in emulsion polymerization, since it controls to a great extent particle nucleation, secondary nucleation, particle size distribution, etc. For this reason, it is essential to have reliable correlations and parameters for predicting surfactant adsorption when developing models of these systems.

Under equilibrium conditions, the surfactant concentrations in the aqueous phase and at the polymer-water interface are uniquely related by the adsorption isotherm [3]. A number of authors have determined adsorption isotherms of (ionic and non-ionic) surfactants on polymer latexes, but the large majority of these studies have been done for polystyrene (PS) [4-12], given its widespread use as model colloid. Consequently, there is a clear need for data on other important systems, of which PVC is an example.

Various methods have been proposed to obtain adsorption isotherms of surfactants on polymer particles. Usually, such methods rely on the monitoring of the equilibrium concentration of free surfactant in the aqueous phase. For the particular case of ionic emulsifiers, we can mention a few alternatives. Paxton [4] measured the adsorption of SDBS on PS and poly(methyl methacrylate) latexes from surface tension titration curves. Brown and Zhao [5] determined adsorption isotherms of the SDS-PS system, at different ionic strengths, by measuring the surface tension of the aqueous phase, after centrifugation of the latex. Zwetsloot and Leyte [6] determined the adsorption isotherm of SDBS on PS from measurements of the latex conductivity (without phase separation). The validity of this approach has nevertheless been 
questioned by Stubbs et al. [13], who claim that the small effect of the partitioning of the anion upon the latex conductivity is hidden by the presence of higher concentrations of more conductive sodium ions in the aqueous phase. Turner et al. [9] investigated the adsorption of SDS on flat PS surfaces by neutron reflection and attenuated total reflection infrared spectroscopy. Colombié et al. [10] determined the adsorption of SDS on PS latexes by making use of the serum replacement technique in conjunction with conductivity measurements of the exit stream of the replacement cell. The same system was studied by Lin et al. [11], but using measurements of the latex surface tension. Sefcik et al. [12] investigated the SDS-PS system by analyzing a small amount of filtrate, obtained through utrafiltration, via ion chromatography.

The objective of the current work is to study the adsorption of the two surfactants (SDS and SDBS) most used in the production of PVC latexes by emulsion polymerization. Hopefully, this will provide useful data for the modeling of such process. The technique put forward by Paxton [4] is employed to determine the adsorption isotherms. 


\section{Experimental}

\subsection{Materials}

Vinyl chloride monomer was supplied by Arkema, with a purity of $99.97 \%$, as indicated by gas chromatography. Ammonium persulfate, APS, (ACS, Acros Organics) was used as initiator. The anionic surfactants, sodium dodecyl sulfate (99\%, Acros Organics) and sodium dodecyl benzenesulfonate (88\%, Acros Organics), were used as received. No attempt to purify the emulsifiers was made, since our purpose was to study the adsorption of SDS and SDBS as they are used in typical emulsion polymerization runs. Deionized water was used throughout the work.

\subsection{Latex Preparation and Characterization}

The PVC latex particles were produced via batch emulsion polymerization [14], carried out at $50^{\circ} \mathrm{C}$ in a $1.5 \mathrm{~L}$ stainless steal reactor. The following recipe was used: 920 $\mathrm{g}$ of water, $106 \mathrm{~g}$ of monomer, $0.63 \mathrm{~g}$ of SDS and $0.23 \mathrm{~g}$ of APS. The polymerization was conducted for $6 \mathrm{~h}$ (92\% conversion), after which the latex was stripped under vacuum for complete removal of the remaining monomer.

Surfactant and residual initiator were removed from the latex by repeatedly passing it over a mixture of anionic and cationic ion-exchange resins (Dowex MR-3, Aldrich). The withdrawal of the ionic species was monitored by measuring the latex conductivity, and it was assumed that the washing step was complete when the conductivity no longer decreased with successive passes over the resin.

At the end of this procedure the polymer content of the latex was $9.1 \mathrm{wt} \%$, as determined by thermogravimetry. By dilution, four other latex solutions were prepared, with polymer contents of 7.0, 5.0, 3.0 and $1.0 \mathrm{wt} \%$. 
The particle size distribution of the latex was determined by static light scattering (Coulter LS230). The latex was found to be nearly monodisperse (PI=0.04), with number average diameter $d_{1,0}=95 \mathrm{~nm}$ and volume-to-surface average diameter $d_{3,2}=104 \mathrm{~nm}$. The surface charge density of the latex was measured by titrating the washed latex with $\mathrm{NaOH}$ until the isoelectric point was reached. A value of $7 \mathrm{mC} / \mathrm{m}^{2}$ was found.

\subsection{Conductivity Measurements}

Conductometric titrations were done to determine the critical micellar concentration (CMC) and the surface concentration of emulsifier at saturation. Usually, $60 \mathrm{~g}$ of cleaned latex $(9.1 \mathrm{wt} \%)$ or deionized water were placed in a stirred thermostated cell and the emulsifier solution was added using a motor-driven syringe at a rate of 0.5 $\mathrm{mL} / \mathrm{min}$. The conductivity of the solution was monitored with a Copenhagen CDM 83 conductivity meter, equipped with a platinum cell. Titrations were conducted at 20.0, 40.0 and $50.0 \pm 0.5^{\circ} \mathrm{C}$.

\subsection{Surface Tension Measurements}

The surface tension measurements were performed with a Krüss K12 automatic tensiometer, equipped with a Du Noüy ring and a Metrohm 665 Dosimat. Normally, 20 $\mathrm{g}$ of latex with a given polymer content were added to a small glass vessel and after 10min wait for thermal equilibrium the series of measurements started. Emulsifier was automatically added as a solution in water, and each increment of emulsifier was followed by 3 min stirring, after which 3 surface tension readings were made. This procedure was repeated up to the end-point, beyond which more surfactant produced 
only a slight decrease of the surface tension. All surface tension measurements were made at $20 \pm 2^{\circ} \mathrm{C}$. Cleaning the ring during titration was found to be unnecessary. 


\section{Results and discussion}

Table 1 summarizes the data obtained from the conductometric titrations, namely the CMC, the surface concentration at saturation $\left(\Gamma_{\text {sat }}\right)$ and the area per surfactant molecule $\left(a_{\mathrm{s}}=\left(\Gamma_{\mathrm{sat}} N_{\mathrm{A}}\right)^{-1}\right)$. Note that no $\Gamma_{\text {sat }}$ or $a_{\mathrm{s}}$ values are reported for SDBS. This is because the change of slope at the saturation point is rather faint with this surfactant, making it very hard to determine the breakpoint in an objective manner, particularly when titrating the latex. In addition, the presence of impurities (homologs with different alkyl chain lengths) is likely to exacerbate the situation.

The $a_{\mathrm{s}}$ values found for the SDS-PVC system are somewhat beyond the range (37-42 $\AA^{2}$ ) reported by Palmgren [15]. However, as shown subsequently, our results have been confirmed by surface tension measurements, which reinforces their validity. With respect to the CMC of SDBS, the values obtained lie between the value for pure SDBS (1.2 mM) [16] and the value reported for a commercially available product (3.0 $\mathrm{mM}$ ) [6]. Since the CMC decreases with increasing hydrophobic chain lengths [17], this probably indicates that the SDBS grade used in this work contains a certain amount of homologs with shorter alkyl chains. Concerning the effect of the temperature, we see that it is small, but definite: the CMC increases and $\Gamma_{\text {sat }}$ decreases with increasing temperature.

The adsorption isotherms were determined from a series of surface tension titration curves performed at different polymer contents, according to Paxton's method [4]. The latter is based on the assumption that equal surface tensions indicate equal equilibrium emulsifier concentrations in the aqueous phase $\left([S]_{\mathrm{w}}\right)$ and hence equal values of adsorbed emulsifier $(\Gamma)$. The surface tension titration curves of the PVC latexes with SDS and SDBS are shown in Fig. 1. Surface tension measurements were only performed at room temperature, because of the experimental difficulties of 
controlling water evaporation at higher temperatures. Note that the initial value of the latex surface tension is independent of the polymer content and very close to the value for pure water at the temperature of the measurements, as expected.

From the curves in Fig. 1, we can obtain the value of the total surfactant concentration $[S]$, at a given surface tension, for each polymer content. In addition, we have the surfactant material balance equation,

$$
[\mathrm{S}]=[\mathrm{S}]_{\mathrm{w}}+\Gamma \frac{A_{\mathrm{p}}}{V_{\mathrm{w}}}
$$

where $A_{\mathrm{p}}=\left(6 m_{\mathrm{p}}\right) /\left(\rho_{\mathrm{p}} d_{3,2}\right)$ is the area of the polymer particles and $V_{\mathrm{w}}$ is the volume of the aqueous phase. Note that $A_{\mathrm{p}} / V_{\mathrm{w}}$ is directly related to the latex polymer content. Therefore, by plotting [S] as a function of $A_{\mathrm{p}} / V_{\mathrm{w}}$, for a given surface tension, one can easily estimate the corresponding values of $[\mathrm{S}]_{\mathrm{w}}$ and $\Gamma$.

In Fig. 2, the total emulsifier concentrations determined from Fig. 1 are plotted as a function of $A_{\mathrm{p}} / V_{\mathrm{w}}$ for the chosen values of surface tension (the spacing is 2 $\mathrm{mN} / \mathrm{m}$ ). In this figure, the lines represent linear regressions to the data, according to Eq. (1). The smallest values of the determination coefficient are $R^{2}=0.994$ (Fig. 2a) and $R^{2}=0.999$ (Fig. 2 b), which quantitatively confirms the visible linearity of the data and supports the assumptions of Paxton's method. Finally, the adsorption isotherms, constructed from the intercept and slope of the aforementioned linear regressions, are depicted in Fig. 3.

Several equations have been used to describe and interpret the adsorption of surfactants on colloids. In particular, $\mathrm{Zhu}$ and $\mathrm{Gu}$ [3] have proposed a general adsorption equation, based on a two-step adsorption model, capable of representing 
Langmuir-type, S-type and two-plateau-type isotherms. A useful form of the general expression is the following limiting case,

$$
\Gamma=\Gamma_{\infty} \frac{K[\mathrm{~S}]_{\mathrm{w}}{ }^{n}}{1+K[\mathrm{~S}]_{\mathrm{w}}{ }^{n}}
$$

where $\Gamma_{\infty}$ is the limiting surface concentration, $n$ is said to be the aggregation number of the hemimicelles (but is in fact an adjustable parameter), and $K$ is the product of the equilibrium constants for the first and second adsorption steps. The Langmuir isotherm is recovered when $n=1$.

This 3-parameter equation was used to fit the experimental adsorption data. The curves thus obtained are plotted as solid lines in Fig. 3 and the corresponding parameters are summarized in Table 2 . The calculated values of $\Gamma_{\text {sat }}$ and $a_{\mathrm{s}}$ are also included in Table 2, from which we can see that the $a_{\mathrm{s}}$ value for SDS matches the result previously determined by conductimetry (cf. Table 1 ).

As we can notice in Fig. 3, the experimental data are very well described by Eq. (2). For both surfactants, the value of the parameter $n$ is found to be above unity, indicating a certain degree of deviation with respect to the Langmuir equation. Indeed, although at first sight, one might think the data could also be described by a Langmuir isotherm, a plot of the residuals would clearly show an S-like pattern arising from the slight S-shape of the data not taken into account by the Langmuir equation. Nevertheless, the value obtained for the aggregation number of the hemimicelles $(n=1.33)$ appears too small to be a sign of a two-step adsorption mechanism. It is also interesting to observe that an identical value of $n$ is determined with the two emulsifiers, as if it were a property of the polymer and not of the surfactant. Zwetsloot and Leyte [6] 
also found a low value of $n(=1.5)$ when investigating the adsorption of SDBS on PS particles. These authors suggested that some process, possibly the charges in the polymer surface, could be responsible for the deviations with respect to what would be a Langmuir adsorption mechanism. However, our PVC latex has a very low surface charge density $\sigma=7 \mathrm{mC} / \mathrm{m}^{2}$ (about one order of magnitude less than the latex of Zwetsloot and Leyte) and despite that the deviations persist. Thus, it is not clear at present what might be mechanisms responsible for the observed shape of the isotherms. 


\section{Conclusions}

In this work, we studied the adsorption of SDS and SDBS on PVC latex particles. In particular, we measured the adsorption isotherms of these two emulsifiers from surface tension titration curves performed at different polymer contents. The data thus obtained was fitted to the equation of $\mathrm{Zhu}$ and $\mathrm{Gu}$, the agreement between the calculated curves and the experimental points being very good. Unfortunately, firm conclusions could not be drawn upon the nature of the phenomena concealed behind the actual shape of the isotherms. The correlations obtained can be used, particularly in emulsion polymerization, to estimate the surface coverage of the polymer particles, which is a key parameter to compute the coagulation rate coefficients between the particles.

\section{Acknowledgments}

Hugo M. Vale wishes to thank the Portuguese Science and Technology Foundation for financial support (grant SFRH/BD/10513/2002). 


\section{References}

[1] D. C. Blackley, Polymer latices, science and technology. Fundamental principles, Chapman \& Hall, London, 1997.

[2] R. H. Ottewill, in: J. M. Asúa Ed. Polymeric Dispersions: Principles and Applications, Kluwer Academic Publishers, Dordrecht, 1997, p. 31.

[3] B.-Y. Zhu, T. Gu, Adv. Colloid Interface Sci. 37 (1991) 1.

[4] T. R. Paxton, J. Colloid Interface Sci. 31 (1969) 19.

[5] W. Brown, J. Zhao, Macromolecules 26 (1993) 2711.

[6] J. P. H. Zwetsloot, J. C. Leyte, J. Colloid Interface Sci. 175 (1995) 1.

[7] D. Colombié, K. Landfester, E. D. Sudol, M. S. El-Aasser, J. Colloid Interface Sci. 202 (1998) 554.

[8] M. S. Romero-Cano, A. Martín-Rodríguez, G. Chauveteau, F. J. de las Nieves, J. Colloid Interface Sci. 198 (1998) 266.

[9] S. F. Turner, S. M. Clarke, A. R. Rennie, P. N. Thirtle, D. J. Cooke, Z. X. Li, R. K. Thomas, Langmuir 15 (1999) 1017.

[10] D. Colombié, K. Landfester, E. D. Sudol, M. S. El-Aasser, Langmuir 16 (2000) 7905 .

[11] S.-Y. Lin, C. Dong, T.-J. Hsu, C.-T. Hsu, Colloids and Surfaces A: Physicochem. Eng. Aspects 196 (2002) 189.

[12] J. Sefcik, M. Verduyn, G. Storti, M. Morbidelli, Langmuir 19 (2003) 4778.

[13] J. M. Stubbs, Y. G. Durant, D. C. Sundberg, Langmuir 15 (1999) 3250.

[14] J. Ugelstad, P. C. Mork, P. Dahl, P. Rangnes, J. Polym. Sci., Part C 27 (1969) 49.

[15] O. Palmgren, in: I. Piirma, J. L. Gordon (Eds.), Emulsion Polymerization, American Chemical Society, Washington, 1976, p. 258.

[16] J. W. Gershman, J. Phys. Chem. 61 (1957) 581.

[17] I. Piirma, S.-R. Chen, J. Colloid Interface Sci. 74 (1980) 90. 


\section{Tables}

Table 1

Adsorption parameters of SDS and SDBS on PVC particles at different temperatures, as determined by conductimetry

\begin{tabular}{|c|c|c|c|c|}
\hline \multirow[b]{2}{*}{$\mathrm{T}\left({ }^{\circ} \mathrm{C}\right)$} & \multicolumn{3}{|c|}{ SDS } & \multirow{2}{*}{$\begin{array}{c}\text { SDBS } \\
\mathrm{CMC}(\mathrm{mM})\end{array}$} \\
\hline & $\mathrm{CMC}(\mathrm{mM})$ & $\Gamma_{\text {sat }}\left(\mu \mathrm{mol} / \mathrm{m}^{2}\right)$ & $a_{\mathrm{s}}\left(\AA^{2}\right)$ & \\
\hline 20 & 8.3 & 3.6 & 47 & 1.8 \\
\hline 40 & 8.7 & 3.2 & 52 & 1.9 \\
\hline 50 & 9.1 & 3.1 & 54 & 2.1 \\
\hline
\end{tabular}

Table 2

Parameters obtained by fitting Eq. (2) to experimental data on the adsorption of SDS and SDBS on PVC particles at $20^{\circ} \mathrm{C}$

\begin{tabular}{lccccc}
\hline & $\Gamma_{\infty}\left(\mu \mathrm{mol} / \mathrm{m}^{2}\right)$ & $K\left(\mathrm{M}^{-n}\right)$ & $n$ & $\Gamma_{\mathrm{sat}}\left(\mu \mathrm{mol} / \mathrm{m}^{2}\right)$ & $a_{\mathrm{s}}\left(\AA^{2}\right)$ \\
\hline SDS & 5.9 & $8.4 \times 10^{2}$ & 1.33 & 3.5 & 47 \\
SDBS & 4.3 & $1.8 \times 10^{4}$ & 1.33 & 3.3 & 50 \\
\hline
\end{tabular}




\section{Figure Captions}

Fig. 1. Surface tension titration curves at various polymer contents, with SDS (a) and SDBS (b).

Fig. 2. Plots of the total surfactant concentration as a function of polymer surface per unit volume at constant surface tension, for SDS (a) and SDBS (b).

Fig. 3. Adsorption isotherms of SDS (a) and SDBS (b) on PVC particles, at $20^{\circ} \mathrm{C}$. The lines represent the fitted isotherms. 


\section{Figures}

Figure 1a:

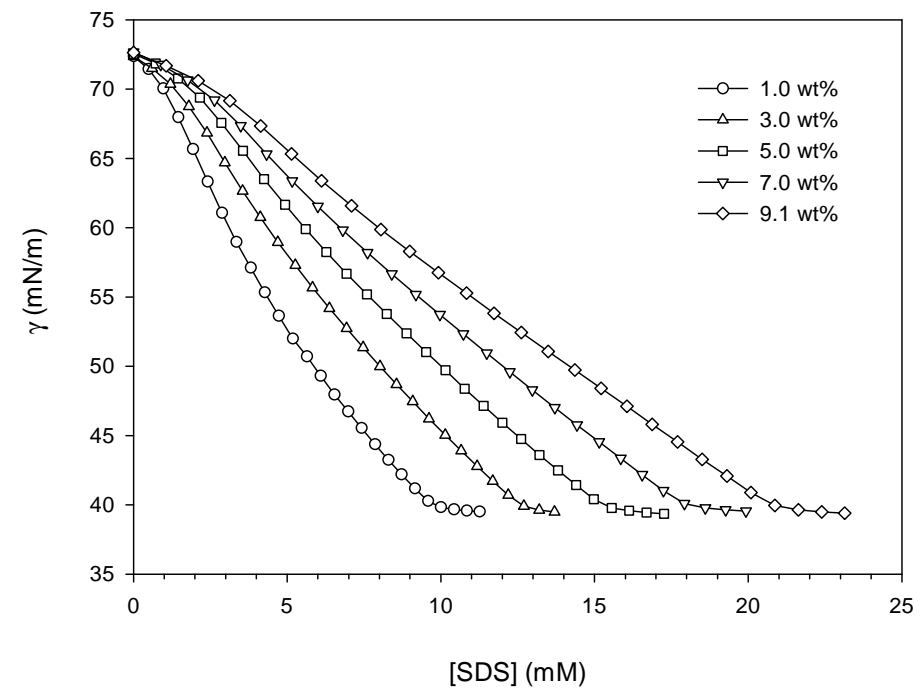

Figure 1b:

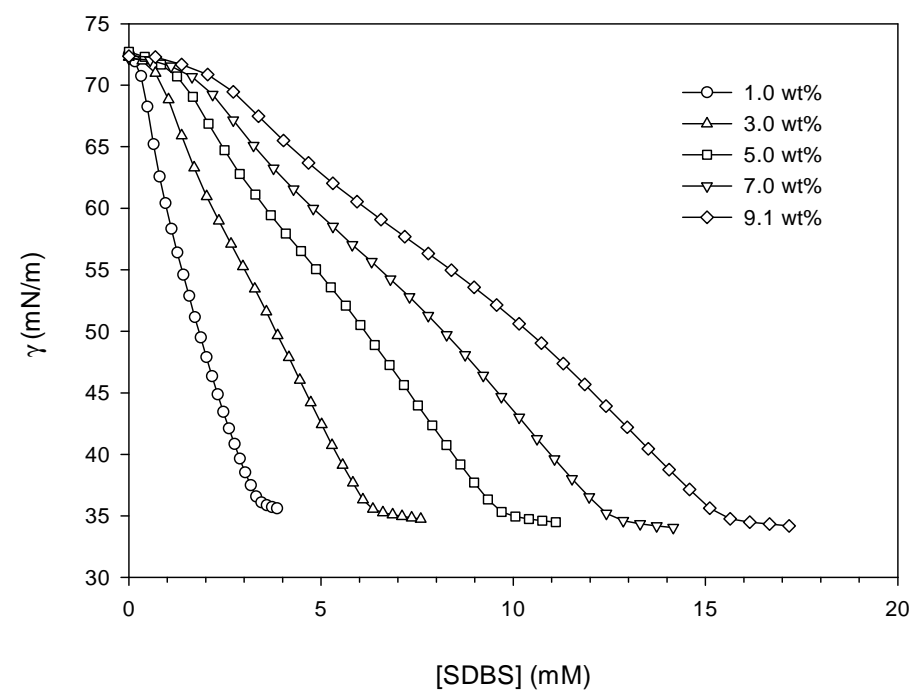


Figure 2a:

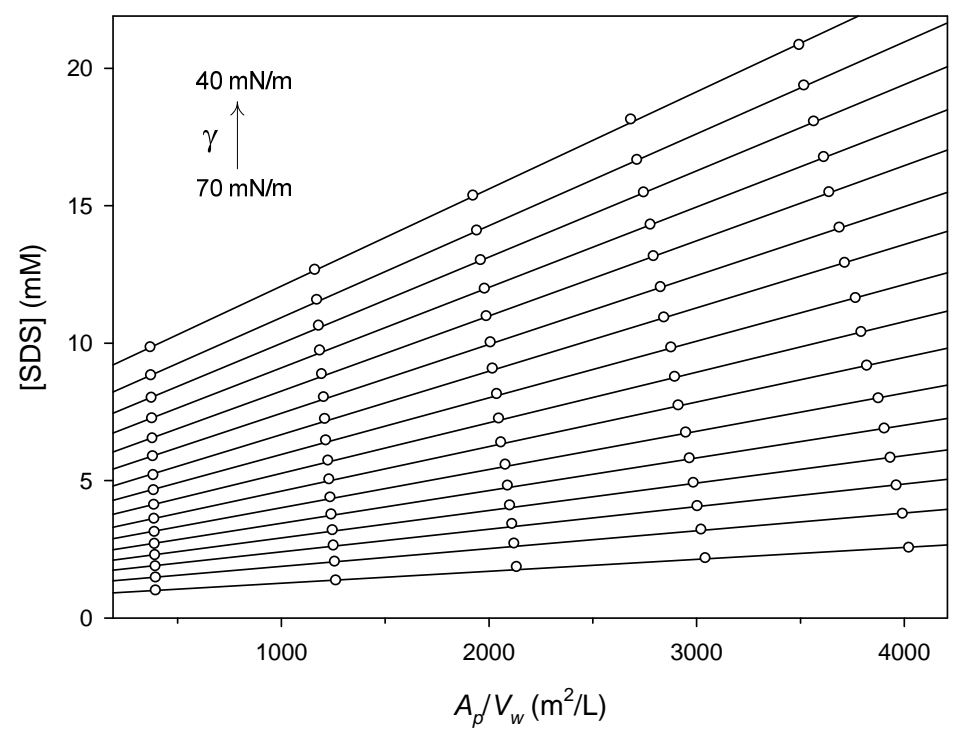

Figure 2b:

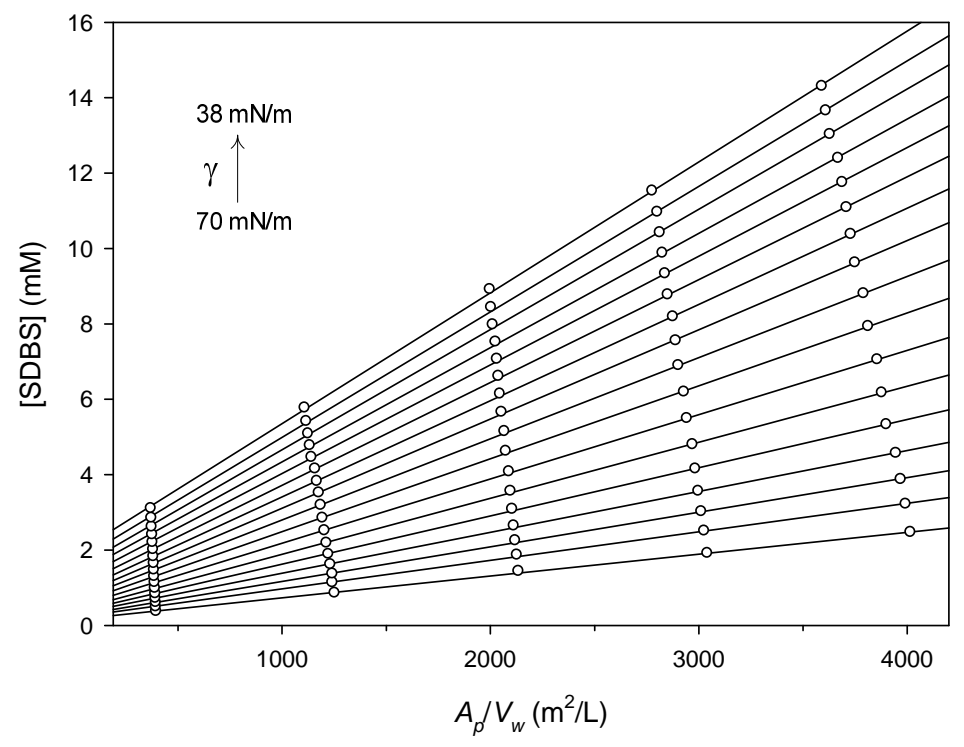


Figure 3a:

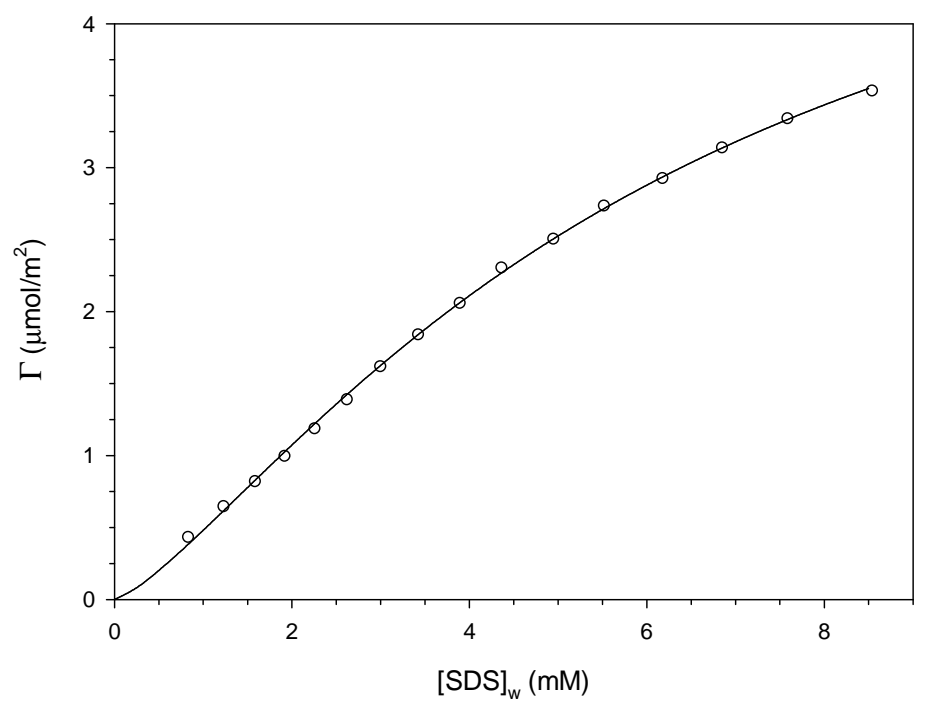

Figure 3b:

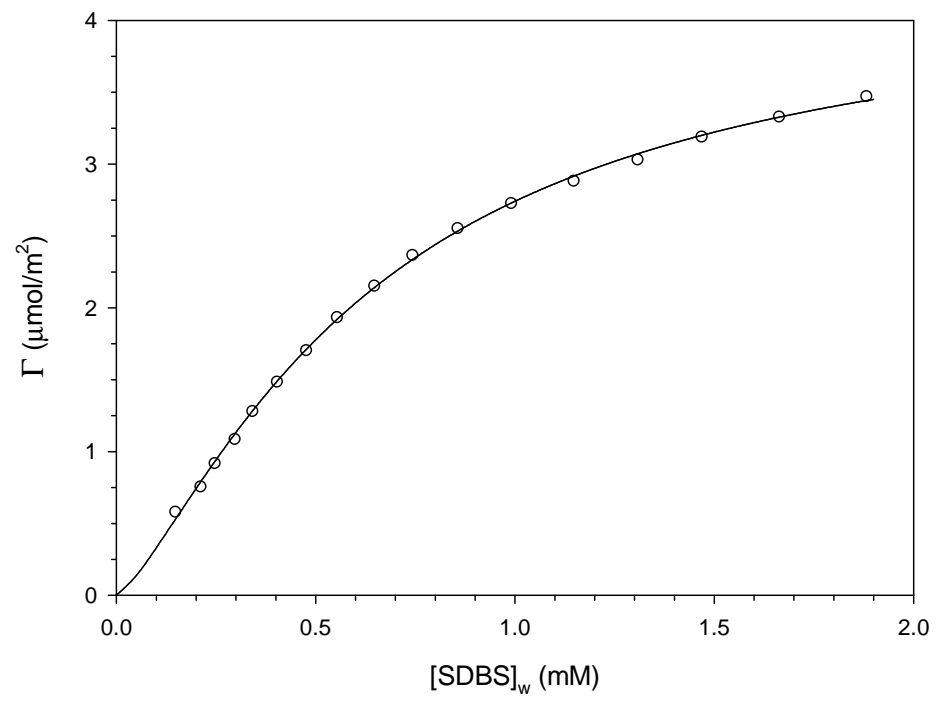

